Article

\title{
Rice Hulls as a Renewable Complex Material Resource
}

\author{
Irina Glushankova ${ }^{1}$, Aleksandr Ketov ${ }^{1, *}$, Marina Krasnovskikh ${ }^{2}$, Larisa Rudakova ${ }^{1}$ and \\ Iakov Vaisman ${ }^{1}$ \\ 1 Department of Environmental Engineering, Perm National Research Polytechnic University, \\ Perm 614990, Russia; irina_chem@mail.ru (I.G.); larisa@eco.pstu.ac.ru (L.R.); eco@pstu.ru (I.V.) \\ 2 Department of Inorganic Chemistry, Perm State National Research University, Perm 614000, Russia; \\ krasnovskih@yandex.ru \\ * Correspondence: alexander_ketov@mail.ru; Tel.: +7-902-834-6620
}

Received: 29 March 2018; Accepted: 17 May 2018; Published: 21 May 2018

\begin{abstract}
As a result of rice grain processing, a big amount of waste (up to 20\%) is produced. It is mainly rice hulls. The main components of rice hulls are cellulose, lignin and mineral ash. The mineral ash quantity in rice hulls varies from 15 up to $20 \%$, by weight of the rice hulls. The mineral ash consists of amorphous silica (opal-type). Due to the high content of silica in rice hulls, the material burns with difficulty under natural conditions, and it is biodegradably destroyed only with difficulty, when composted. Utilization of rice hulls then becomes an ecological problem due to huge rice production and its continuous growth. At the same time, the annual quantity of silica content in rice hulls is comparable with the quantity of amorphous silica produced as a mineral resource. The issue of manufacturing cellular glass silica construction materials from rice hulls as a renewable resource is discussed in this paper. The utilization technology is based on an amorphous silicon oxide with the use of energy from the combustion of the organic component of rice hulls.
\end{abstract}

Keywords: rice hulls; amorphous silica; renewable resource; cellular bricks; construction materials

\section{Introduction}

Mankind uses a lot of various mineral resources for the manufacturing of goods. Most of the natural resources are exhaustive and non-renewable. However, rice waste represents a rare exception. Several hundred million tons of rice hulls (or rice husks) are generated annually. This waste material contains two types of resources. The organic part of rice hulls can be oxidized with the receipt of energy and the inorganic remnants, or ash, consists of the amorphous silica applicable for manufacturing various materials. Generation of rice hulls ash is comparable with the silica mineral extracted from the ground as a raw material for many types of products.

Irrigated rice production is one of the most crucial agricultural activities for sustaining our global population, and at the same time, is one of the agricultural sectors that is considered to be most eco-unfriendly [1]. The problem of reusing rice waste, such as husks and straw, also remains unsolved.

Use of rice hulls as a bilateral (energy and mineral) resource is limited due to the difficulties of its combustion and low density. Transportation of rice hulls to industrial centers for generation of energy and high technology processing of the resulting ash is not economically effective. Moreover, rice production is concentrated in agricultural regions with underdeveloped industries. It is difficult to implement the construction of powerful electrical stations or enterprises for deep reusing of rice hulls ash. However, the uniqueness of rice hulls consists in combining the energy and renewable material resources in one material. The required construction material made from rice hulls ash could be produced using the energy of the same rice hulls. 


\section{Materials and Methods}

Rice hulls produced in the Krasnodar region of Russia were used. Complex research provided a successful analysis of the resource potential of rice hulls. Pyrolysis of the rice hulls was performed with a STA 449 F1 device for the synchronous thermal analysis (Netzsch, Selb, Germany), allowing the thermal analysis of a sample to be performed with simultaneous recording of its thermal gravimetric and calorimetric characteristics. The gaseous products were analyzed with a QMS 303 CF Aeolos mass spectrometer (Netzsch, Selb, Germany). The results were processed using the appropriate software. An X-ray diffractometer Shimadzu XRD-7000 (Shimadzu Corporation, Kyoto, Japan) and a scanning electron microscope HITACHIS-3400 (Hitachi High-Technologies Corporation, Hitachinaka, Japan) were used.

The cellular structure materials were prepared from rice hulls ash and sodium hydroxide. The standard rice hulls ash, containing $6.5 \%$ of carbon, was additionally oxidized in rich oxygen atmosphere containing $0.2 \%$ of carbon after oxidation at $550{ }^{\circ} \mathrm{C}$. The samples were prepared by mixing the $14.5 \mathrm{M}$ solution of sodium hydroxide and the low-carbon ash by impregnation of the moisture capacity. The resulting mixture was dried at $90{ }^{\circ} \mathrm{C}$ and then calcinated at $780{ }^{\circ} \mathrm{C}$. The prepared composition was heated at $780{ }^{\circ} \mathrm{C}$ for one hour.

\section{Results}

A key to the efficient development of rice hulls reuse is exploitation of the full potential of the organic and inorganic material. The initial rice hulls are shown in Figure 1a. The energy generation is possible by oxidation of the rice hulls in the flame. Burning proceeded slowly and with difficulty due to the high concentration of inorganic silica and the low permeability of the husk layer. The rice hulls ash that appears during the usual process of burning has a lot of residual carbon (Figure 1b).

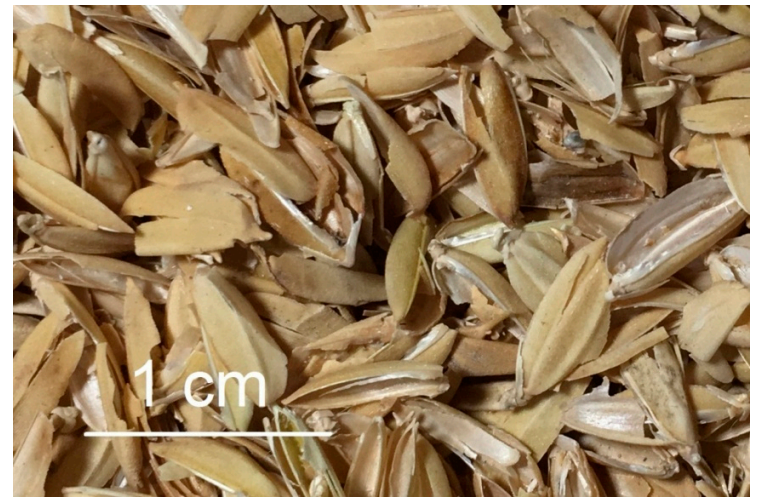

(a)

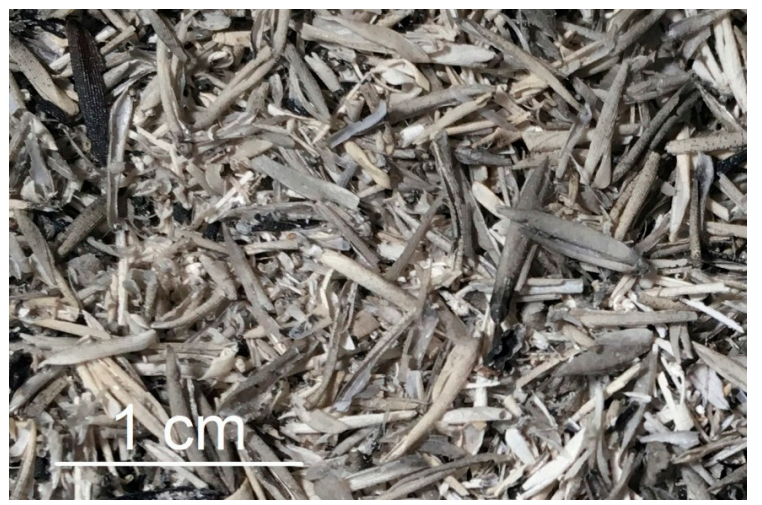

(b)

Figure 1. (a) The rice hulls; (b) The rice hulls ash.

Generation of energy is more effective in intensive methods, for example, in pulverized fuel-fired steam. The whole organic part is oxidized in this process and it is possible to separate the energy potential of the rice hulls as much as the potential of any other organic waste. Pyrolysis without air leads to obtaining flying organic substances and coal; both can be separately used later as fuel. The resulting ash consists of amorphous silica. All these components of rice waste are considered usually as independent resources.

\subsection{Weight Loss of a Sample in the Process of Pyrolysis}

The thermogravimetry analysis was carried out in air and in the inert atmosphere of argon. Figure 2 shows the corresponding thermogravimetry (TG) and differential thermogravimetry (DTG) curves. One can observe three stages of decomposition for a sample in air atmosphere. 


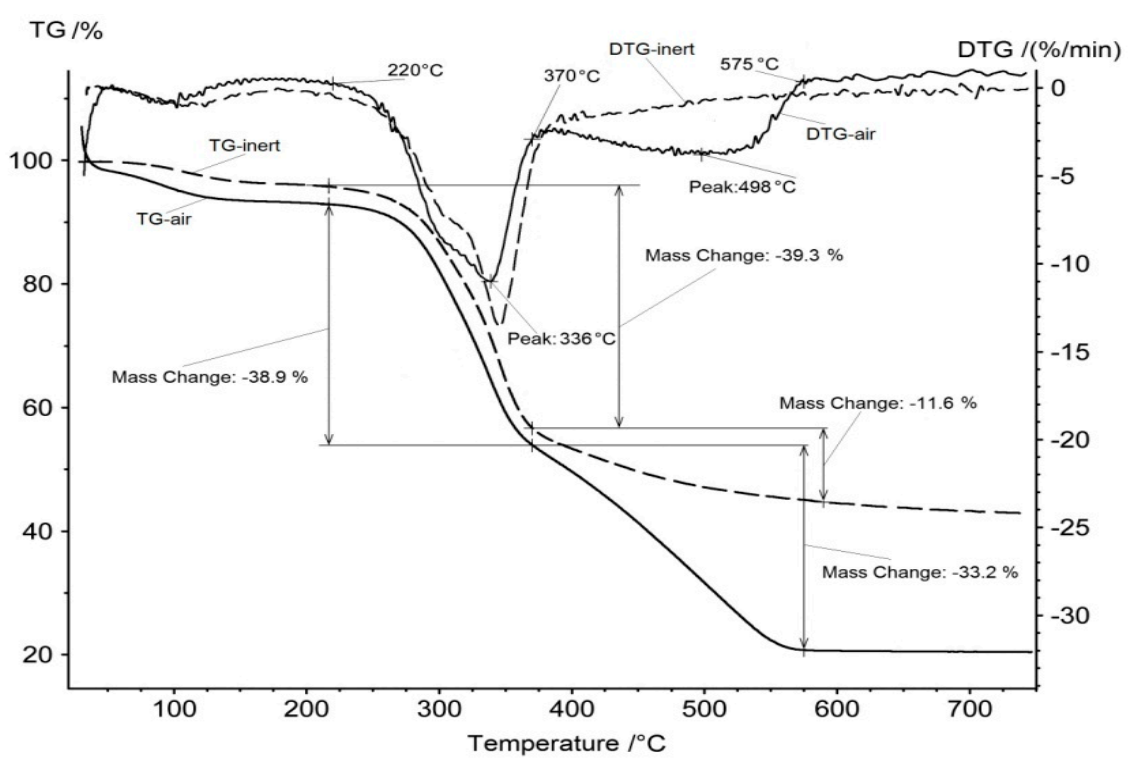

Figure 2. TG and DTG curves for rice hulls in air and in inert atmosphere.

The first stage of mass loss at $80-120{ }^{\circ} \mathrm{C}$ can be attributed to the removal of physical water. Further heating of the dry material does not lead to noticeable changes up to a temperature of $220{ }^{\circ} \mathrm{C}$. The second stage of mass reduction is observed from approximately this temperature up to a temperature of $370^{\circ} \mathrm{C}$. This effect can be explained by the decomposition of the organic component down to carbon and the removal of volatile organic compounds from the sample. This version is confirmed by the TG and DTG curves similarity at the second stage and their difference at temperatures above $370{ }^{\circ} \mathrm{C}$, when a pronounced third stage of mass loss is observed on the TG curve, for the sample in air atmosphere. However, there is no similar effect of mass loss above $370{ }^{\circ} \mathrm{C}$ for the sample in argon atmosphere.

The carbon, which remained after the removal of volatile organic compounds, is intensively oxidized by air oxygen at the third stage, at temperatures of $370-575{ }^{\circ} \mathrm{C}$. The residual carbon remains unchanged when the sample is heated in an argon flow; the slight decrease in mass of the TG curve, in this case, can be explained by the presence of trace amounts of oxygen in the inert gas.

Thus, in the process of heating the rice hulls, three temperature intervals can be distinguished. At the first stage of $80-120^{\circ} \mathrm{C}$, the material is dried and its water is removed. At the second stage, above $220^{\circ} \mathrm{C}$, volatile organic compounds are removed from the material; this process is completed at $370{ }^{\circ} \mathrm{C}$, when only carbon and inorganic ash remain in the material. At the third stage, from $370{ }^{\circ} \mathrm{C}$ to $575{ }^{\circ} \mathrm{C}$, carbon oxidation occurs in the presence of oxygen. After the combustion of all the carbon, the remaining mass of about $20 \%$ of the weight of the initial sample is non-combustible residue ash, which is supposed to be composed of silica.

\subsection{Gases Mass Spectrum Data}

This way of decomposition is confirmed by the mass spectrum data presented in Figures 3 and 4. Acetone, acetic acid and furan are the most typical products of cellulose and wood pyrolysis. Observation shows that compounds are evolved only at the second stage of the process with a very narrow interval: $325-341-347^{\circ} \mathrm{C}$. There is an absence of any flying organic substances discharged at the third stage. 


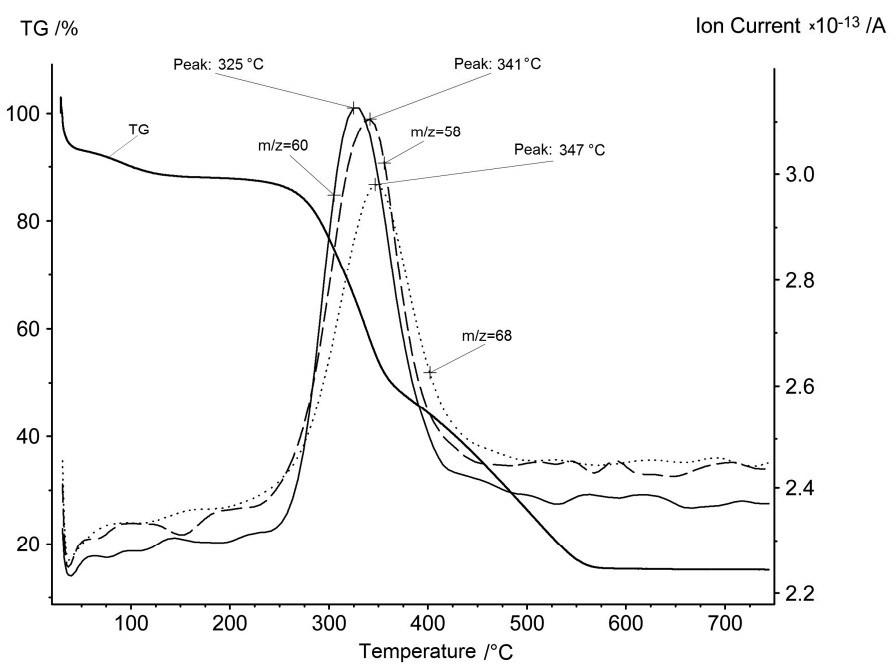

Figure 3. Mass spectrum ion current of $m / z=58$ (acetone), $m / z=60$ (acetic acid) and $m / z=68$ (furan) synchronously with the TG curve of the rice hulls in air.

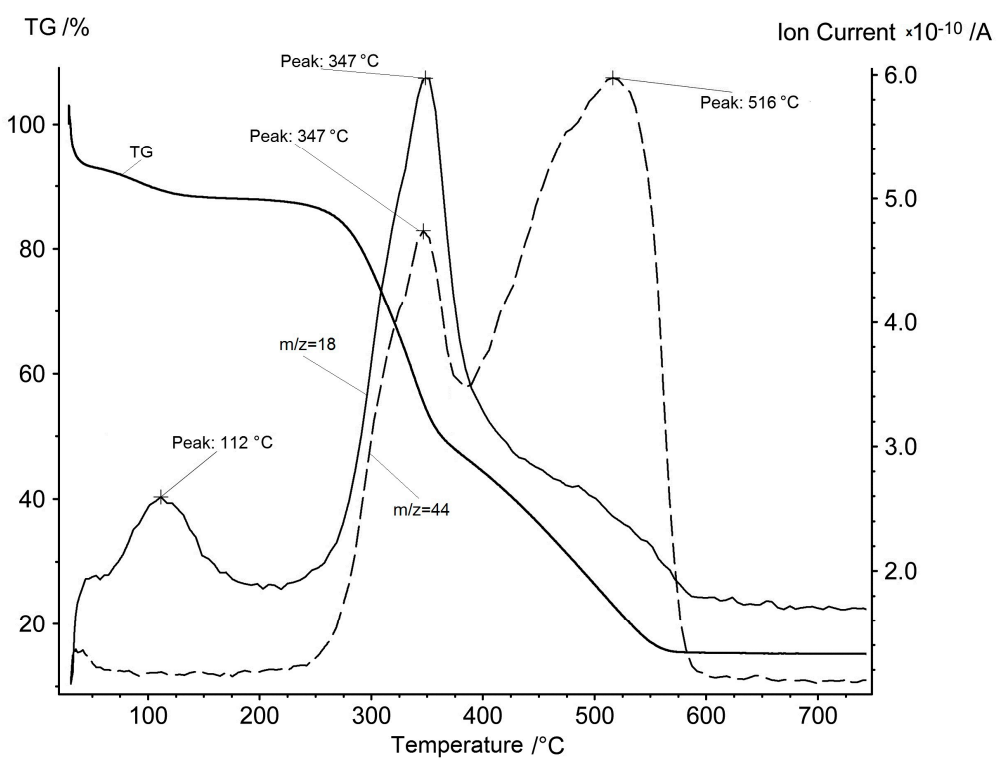

Figure 4. Mass spectrum ion current of $m / z=18$ (water) and $m / z=44$ (carbon dioxide) synchronously with the TG curve of the rice hulls in air.

The evolution of water and carbon dioxide looks very different here compared with inorganic substances. Water steam evolution occurs for the first time at low temperatures of $70-150{ }^{\circ} \mathrm{C}$ in the first stage and it corresponds to the physical water evaporation. The aforementioned second stage of mass loss on the TG curve is attributed to the removal of volatile organic compounds. It is natural to assume that in the presence of oxygen in the atmosphere these compounds will be oxidized to water and carbon oxides. Indeed, the ion currents of water and carbon dioxide have characteristic peaks in the temperature range of the second stage, with a maximum at $347^{\circ} \mathrm{C}$.

If the third stage of mass loss of a sample in the presence of oxygen is attributed to pyrocarbon oxidation, as it was suggested above, then in the appropriate temperature range, one should assume the presence of carbon dioxide alone in the gas phase and the absence of water vapor. Indeed, on the ion current curves, a peak is observed only for the ion current of carbon dioxide, with a maximum at $516^{\circ} \mathrm{C}$. 
Therefore, an assumption concerning the nature of the three stages of the rice hulls mass loss upon heating is confirmed by the results of mass spectroscopy. When the rice hulls are heated, the physical water is removed first, then the volatile organic compounds, and only then the remaining pyrolytic carbon is oxidized by oxygen.

\subsection{Calorimetry of Oxidation}

Taking into account the two-stage mechanism of oxidation of the material, one can assume that the maximum heat release will occur within two temperature intervals. The calorimetric and thermogravimetric curves are presented in Figure 5.

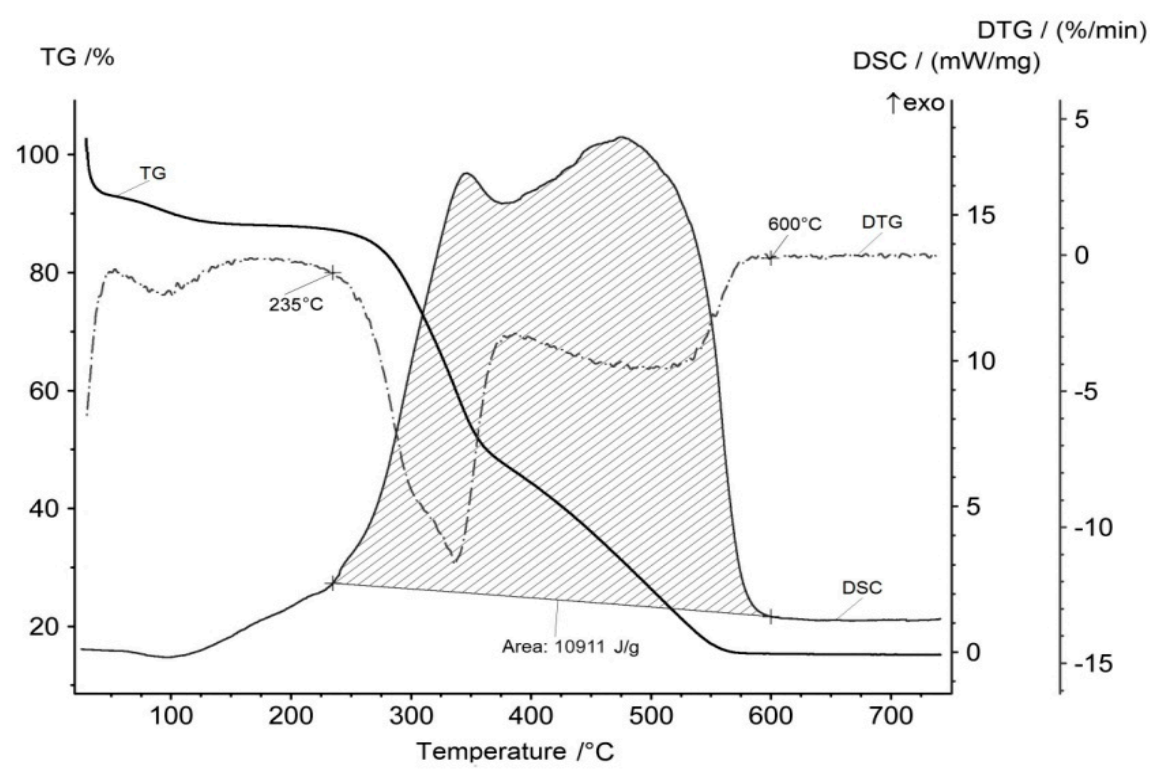

Figure 5. DSC and TG curves of the rice hulls in air.

The beginning of the energy generation process is correlated with that of the flying organic substances evolution at $235{ }^{\circ} \mathrm{C}$ and that of the water and carbon dioxide production. The end of the energy generation process is correlated with that of the carbon dioxide production at $600{ }^{\circ} \mathrm{C}$. There are two maximums on the DSC curve that correspond to the maximums of the flying organic compounds oxidation and carbon oxidation processes. Integration of the DSC curve allows us to calculate the amount of released energy during the process of oxidation. This value is $10.9 \mathrm{MJ} / \mathrm{kg}(3.03 \mathrm{~kW} \cdot \mathrm{h} / \mathrm{kg})$.

The conclusion shows that one kilogram of rice hulls can be a source of $10.9 \mathrm{MJ}$ of heat produced in the process of burning. The same amount of rice hulls can be a source of approximately 200 grams of amorphous silica. This potential could be the basis for an autonomous technology of reusing rice hulls.

\subsection{Structure of the Rice Hulls Ash}

Free firing of rice hulls leads to ash with a high quantity of carbon, as it is possible to see in Figure 6. Thermogravimetry analysis of this ash shows the content of carbon to be $6.5 \%$. The reduction of carbon content in resulting ash is possible by various methods. One can increase the concentration of oxygen; however, the most technologically correct method is the use of a pulverized burning system. Oxidation in rich oxygen atmosphere was used for preparation of the ash, with the content of carbon reduced to $0.2 \%$. The sample of the resulting silica product is shown in Figure 7 . The low content of carbon in the sample is obvious. 


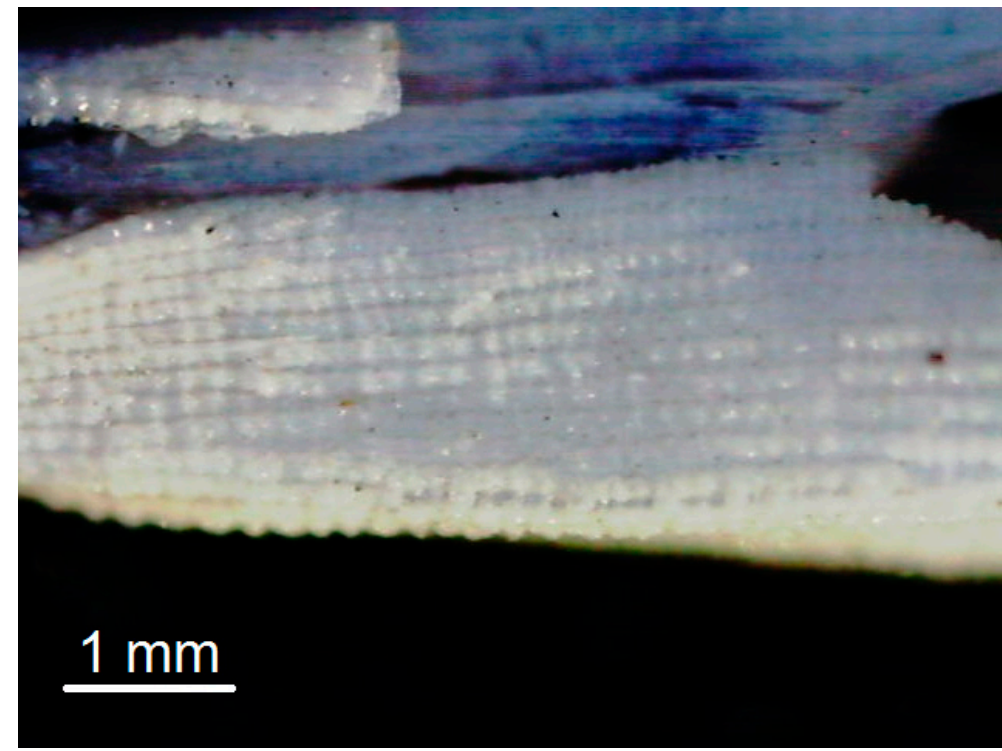

Figure 6. Rice hulls ash prepared in rich oxygen atmosphere.

a

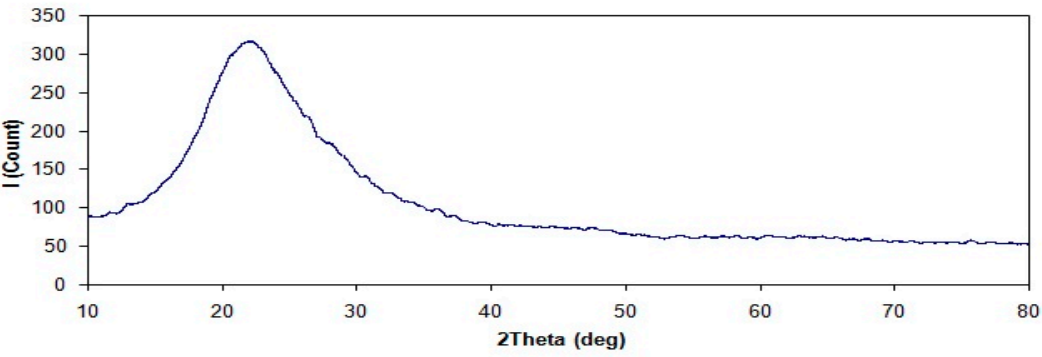

b

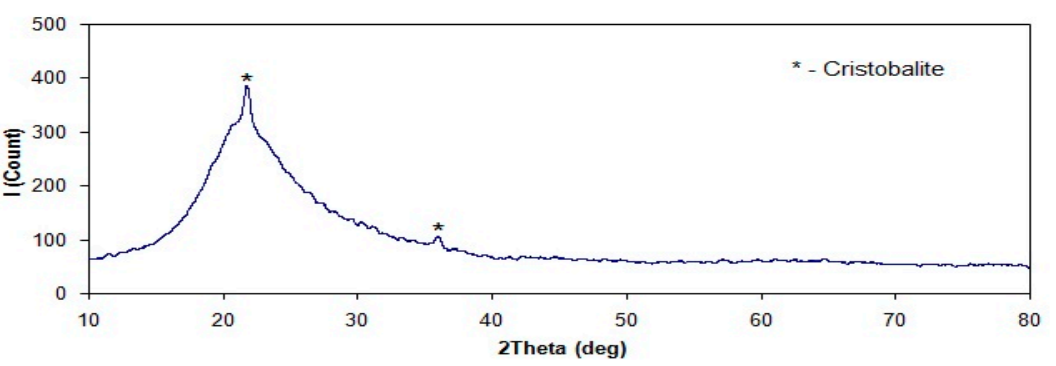

Figure 7. X-ray diffractogram of rice hulls ash prepared in usual atmosphere (a) and of rice hulls ash prepared in rich oxygen atmosphere $(\mathbf{b})$.

The results of the X-ray diffraction analysis are shown in Figure 7; they confirm that the sample obtained by burning in the usual atmosphere is amorphous silica. Burning in the oxygen-rich atmosphere resulted in forming a cristobalite phase in the silica sample. Presumably, this fact is due to high temperatures of burning in cases of high concentrations of oxygen.

Amorphous silica is achieved as a result of burning the rice hulls. Intensification of the burning process and the corresponding increase of temperature in the flame lead to the formation of a cristobalite phase in the ash. However, the cristobalite content is too low and this crystal phase is unlikely to interfere in further processing of the amorphous silica. 


\subsection{Foamed Structure Material from Rice Hulls Ash}

The amounts of gases, which evolved in the process of glass formation from polysilicates at temperatures of glass thermoplasticity, can be enough for the creation of cellular glass. Since the synthesis of glass from a polysilicate chain is essentially the process of eliminating water, it has been found that steam will be the main gas evolved in the course of heat treatment of an alkali-silica composition [2,3].

The cellular structure materials have been prepared according to the above-mentioned procedure, using rice hulls ash and sodium hydroxide. At temperatures of glass thermoplasticity, the steam can actively oxidize carbon through the reaction of steam conversion [4]. The presence of carbon in silica ash promotes the increase of gas formation inside the material during heat treatment.

The obtained samples have the cellular structure shown in Figure 8. The density of both samples is $210-220 \mathrm{~kg} / \mathrm{m}^{3}$; the effect of the cristobalites presence in one of the samples has not been found.

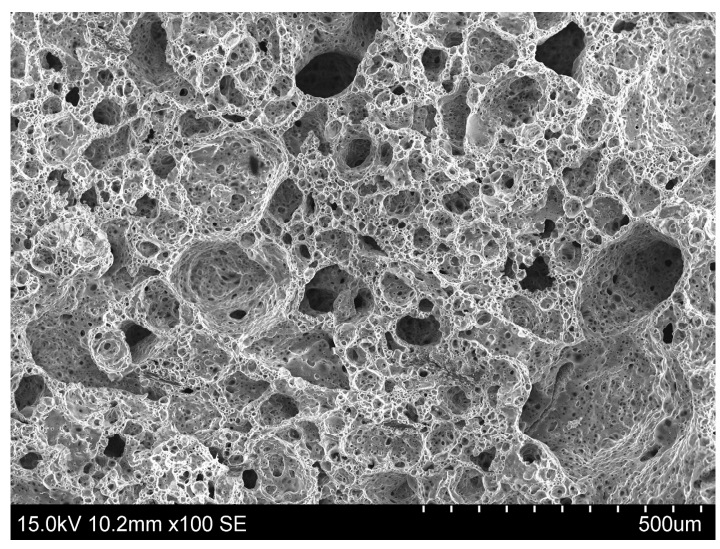

(a)

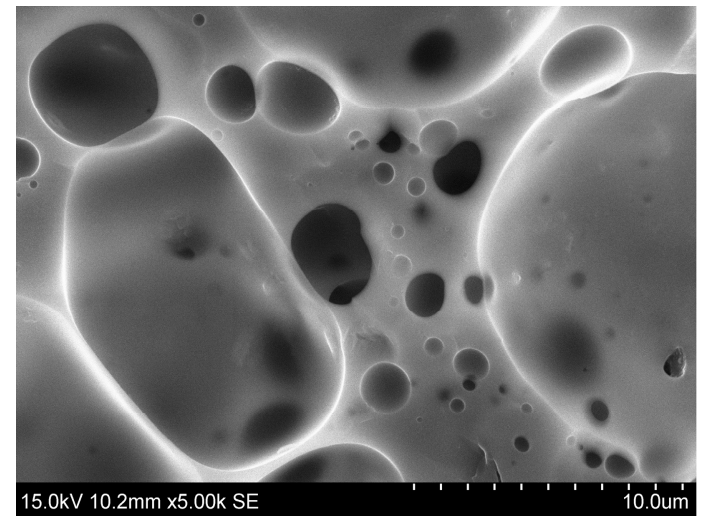

(b)

Figure 8. Structure of the foamed structure material prepared from rice hulls ash with (a) low and (b) high zooming.

\section{Discussion}

Rice hulls are recognized as one of the major potential sources of energy production [5]. Rice hull is known to be an important source of energy, particularly for developing countries where the economy is mainly based on agriculture and forestry. Rice hulls biomass materials maintain net calorific values between $6000 \mathrm{kcal} / \mathrm{kg}$ and $3000 \mathrm{kcal} / \mathrm{kg}$; this is almost half that of natural gas and fossil fuel. The annual worldwide production of rice hulls is estimated to be 100 million tonnes, $90 \%$ of which is generated in developing countries. The proximate and ultimate analyses of the biomass are as follows: Moisture $7.9 \%$, volatile matter $59.5 \%$, fixed carbon $19.9 \%$ and ash $17.1 \%$.

Rice hull, as a major by-product of the rice milling industry, is one of the most commonly available lignocellulosic materials that can be converted into different types of fuels and chemical feedstock through a variety of thermochemical conversion processes. In spite of a high ash content ranging from 15.3 to $24.6 \%$ (dry weight basis) and the high silica content of ash, ranging from 90 to $97 \%$, lower heating values ranging from 13 to $16 \mathrm{MJ} / \mathrm{kg}$ (dry weight basis) have been found [6]. This is why rice hulls are firstly considered as a renewable energy source.

Oxidation of rice hulls, however, proceeds with difficulty. The material has a low bulk density and low calorific values. Nevertheless, it can be used as an admixture to the composition of fuel briquettes with more flammable materials. Briquetting involves the compression of some material into a solid product of a higher bulk density, lower moisture content, uniform size and shape; all the properties that would allow the material to be used as fuel, just like wood or charcoal. To maximize the potential 
of waste paper, commonly produced biomass wastes in the form of carbonized rice hulls and sawdust were considered as key ingredients in the formation of mixtures for briquette production [7].

To intensify oxidation, the bubbling fluidized bed combustion was found to be an effective process [8]. The rice hull combustion was used in a $250 \mathrm{~kW} \cdot \mathrm{h}$ bubbling fluidized bed pilot plant at temperatures of $700,750,800$ and $850{ }^{\circ} \mathrm{C}$ and with fluidization velocities of $0.3,0.4$ and $0.5 \mathrm{~m} / \mathrm{s}$. Low carbon content, up to $1.89 \%$, was obtained in the combustion ashes. Combustion efficiency increased with the combustion temperature; however, it showed some tendency to decrease as fluidization velocity increased.

The actual burning of rice hulls is a multistage process. It was investigated that after evaporation of moisture the sample loses volatiles and carbon only oxidizes higher than $420{ }^{\circ} \mathrm{C}$ [9]. Therefore, it is possible to obtain liquid fuel at the second stage of pyrolysis.

The rice hulls are used as a source of synthetic fuel manufactured by pyrolysis. The main stages of rice hulls pyrolysis are known. TG analysis has been used to determine the existence of organic components in rice hull [10]. It can be seen that an initial weight loss occurs within the range of $50-150{ }^{\circ} \mathrm{C}$, with the weight loss of $1-2 \%$ corresponding to the loss of water and other volatile substances. The second stage reveals a rapid and large weight loss at temperatures between $240-360{ }^{\circ} \mathrm{C}$. This is due to the thermal decomposition of hemicellulose and cellulose as a major organic component of the rice hull. The third stage shows the weight loss of about $26-31 \%$ that could be due to lignin, a thermally more stable aromatic polymer which undergoes gradual decomposition at temperatures between 370 and $600^{\circ} \mathrm{C}$. The residual ash is mainly non-combustible silica $\left(\sim 16 \%,>600^{\circ} \mathrm{C}\right)$. Along with that, the question of gas products of the pyrolysis, according to the mentioned stages, is important, as well as the energy potential of the oxidation stages.

The rice hull was used as a feedstock and pyrolyzed at $475^{\circ} \mathrm{C}$ to obtain the crude bio-oil with a yield of $50 \mathrm{wt}$. \%. This bio-oil was stored in oil tanks and used as a mother liquid for preparation of bio-oil/diesel-oil emulsions. The char content of the bio-oil was only $0.4 \mathrm{wt}$. \% [11]. The properties of the obtained bio-oil were compared with the commercial diesel oil. The higher heating value for the first was $15.4 \mathrm{MJ} / \mathrm{kg}$, and for the second one it was $44 \mathrm{MJ} / \mathrm{kg}$. The bio-oil (pH 3.2) was much more acidic than the diesel oil ( $\mathrm{pH}$ 7.8). It also had a higher kinematic viscosity of $10.2 \mathrm{cSt}$ versus that of $2.9 \mathrm{cSt}$ for the diesel oil. We suppose that the high acidity and higher heating value are connected with the high concentration of water in the composition. Bio-oil is totally different from petroleum oils, it is a complex mixture of water (15-35 wt. \%), solid particles (0.01-3 wt. \%) and hundreds of organic compounds that are classified as acids, aldehydes, ketones, phenols, alcohols, ethers, esters, sugars, furans, nitrogen compounds, as well as large molecular oligomers. Most of the organic compounds are partially soluble in water and separation of the bio-oil from water for quality improvement is an expensive and difficult task.

The rice hulls, as an alternative biomass fuel, are considered to be a potential replacement for fossil fuels such as coal, natural gas and petroleum. The power generation system is a typical pulverized coal-fired steam cycle unit. Co-firing of the biomass fuels with coal leads to a reduction of power generation due to the lower heating value of the biomass than that of fossil fuels and the energy loss with ash [12]. The higher heating value of rice hull is considered to be $14.98 \mathrm{~kJ} / \mathrm{kg}$ and the lower heating value $-13.99 \mathrm{~kJ} / \mathrm{kg}$. The quantity of ash is $14.0 \%$ of the mass. For the biomass /coal co-firing power plant, the energy efficiencies of the boiler and overall plant decrease as the amount of the biomass co-firing increases. From a thermodynamic perspective alone, firing of the biomass is not worthwhile. However, the efficiency decline can be offset by the benefits of biomass co-firing, which include enhanced plant economics, reduced environmental emissions and the substitution of fossil fuels with renewable energy sources.

It is evident that many researchers consider the rice hulls only as a source of synthetic fuel-as any other product of plant origin. However, a number of experts point to the relatively low potential of rice hull, which is connected with a high content of the inorganic component. Indeed, the abovementioned experimental data prove the content of ash in the rice hulls is anomalous for plant products, 
about $20 \%$. This ash is predominantly amorphous silica. Most proposals for re-using the rice hulls are based precisely on the use of this valuable resource.

Due to the high concentration of pure silica in the rice hulls ash, exclusive materials were obtained. A highly pure, small particle-sized and high surface area nano silica powder was prepared from the rice hull, using the alkali extraction, followed by the acid precipitation method [13]. $\beta$-wollastonite was produced from the rice hull ash, as well as calcined limestone via green synthesizing using autoclaving [14]. The rice hull ash, as a silica source, was transformed into MFI-type zeolites (ZSM-5 or Zeolite Socony Mobil-five zeolites) using different structure-directing agents [15].

Utilization of the rice hulls ash as a traditional supplementary cementitious material has become more intense in the concrete industry due to its better durability properties. The rice hulls ash can reduce the quantity of cement required for concrete production [16]. The concrete produced by using up to $30 \%$ of the rice hulls ash as a replacement for cement could be considered as a more environmentally-friendly concrete.

Recently, as a supplement of cement, the utilization of pozzolanic materials in cement and concrete manufacturing has increased significantly. The rice hulls ash as a pozzolanic waste with an alkali activated binder can be used as an alternative to cement [17].

The rice hulls ash is considered to be a promising solid waste material for the production of geopolymers [18]. The high compressive strength materials were obtained from the sodium hydroxide $(\mathrm{NaOH})$ solution and the rice hulls ash at temperatures below waters boiling point.

X-ray diffractograms of the rice hull ash discovered the presence of a low quantity of crystalline phase of cristobalite- $\mathrm{SiO}_{2}$ in mainly amorphous materials. Geopolymers were formed from the rice hull ash and other amorphous alumino-silicate materials by alkaline activation [19]. The rice hull ash composition was found as $\mathrm{SiO}_{2} 70.1 \% ; \mathrm{K}_{2} \mathrm{O} 1.10 \%$ and $\mathrm{CaO} 0.19 \%$ by mass. The residual of $28.6 \%$ was determined as a loss on ignition, or unburned carbon. The rice hull ash decreases the strength of geopolymerization because of the high concentration of unburned carbon in ash.

The porous geopolimer-type compositions were produced using the rice hulls ash with aluminum powder as a foaming agent [20]. Addition of aluminum powder to the composition increases the porosity and decreases the density of the material. The resulting composite acquired a foamed structure.

Ashes derived from the combustion of vegetal wastes represent a secondary raw material for the production of alkali-activated materials. The porous geopolymer composite appears to be a promising thermal insulating material, suitable for being used as a lightweight heat barrier [21]. Such a porous geopolymer represents the best balance in terms of low density $\left(313 \mathrm{~kg} / \mathrm{m}^{3}\right)$ and mechanical strength (0.63 MPa). Besides, it shows an interesting thermal insulating ability, with a thermal conductivity of $0.07 \mathrm{~W} /(\mathrm{m} \cdot \mathrm{K})$ at $30{ }^{\circ} \mathrm{C}$ and an outstanding thermal stability up to $800^{\circ} \mathrm{C}$.

It was found that hydrated polysilicates are foamed in the process of heat treatment by steam emission [22,23]. Cellular glass, or foamed glass, has been obtained as a result of heating polysilicates up to $700-800{ }^{\circ} \mathrm{C}$.

One can conclude that the rice hulls are a renewable source of energy and silica ash, and the combination of these two resources could be used for the production of various useful materials. Rice hull or rice husk is a renewable source of energy and of amorphous silica. The heating value of rice hulls is substantially lower than the same characteristic of fossil fuels. Therefore, rice hulls are uncompetitive with fossil fuels in industrial energy generation. However, the use of burning rice hulls for heat generation is preferable in agricultural regions, and it contributes a lot to protecting the Earth from global warming, by using a huge amount of renewable energy instead of fossil fuels. As an example, let us consider the rice hulls used as a source of thermal energy to produce steam for parboiling raw rice [24]. In this case, the absence of transport costs and the low cost of rice hulls as a fuel leads to effective competition with industrial sources of energy.

A similar solution is possible for using the material resources of rice hulls. The rice hulls ash consists of pure porous amorphous silica. With similar natural materials like tripoli or diatomite, the minerals are extracted from the ground in amounts of hundreds of millions of tons, annually. 
Rice hulls ash cannot compete with mineral analogues of industrial manufacturers; however, it is available for the solution of regional problems in agricultural regions. Use of solid waste for the development of new building materials is known to be an alternative that reduces environmental impact through preservation of natural resources at a regional level [25].

Rice hulls are a unique resource because they combine the material resource of silica, which is available as a raw material for building materials, and an energy source sufficient for manufacturing building materials. Therefore, the manufacturing of construction materials could be set up autonomously in rice agricultural regions, using the rice hulls as a complex resource.

\section{Conclusions}

Rice hulls are an agricultural waste produced in hundreds of millions of tons annually. The material has up to $20 \%$ silica in its composition. Due to the high percentage of ash and the reduced concentration of organic substances, the rice hulls are not effective as an industrial fuel. However, the unique combination of organic and inorganic components, namely, the rice hulls ash, allows us to use rice hulls as a complex raw material for heat insulation of foamed structure material manufacturing in agricultural regions of rice production. The uniqueness of rice hulls as a renewable resource is in its self-sustainability. The material contains not only silica as a basis for building material manufacturing, but also enough fuel for organizing such a manufacture.

Author Contributions: A.K. conceived the experiment and methodology. I.G. performed the experiment, and carried out the data collection, analysis and writing. I.V. and L.R. provided funding, guidance, and editing of the paper. M.K. provided the analysis using thermogravimetry and mass-spectrum.

Acknowledgments: The authors would like to thank Korotaev V.N. and Rossomagina N.I. for their assistance with this project.

Conflicts of Interest: The authors declare no conflict of interest.

\section{References}

1. Uphoff, N.; Dazzo, F.B. Making Rice Production More Environmentally-Friendly. Environments 2016, 3, 12. [CrossRef]

2. Vaisman, Y.I.; Ketov, A.A.; Ketov, P.A. Production of foamed materials from synthesized silicate glasses. Russ. J. Appl. Chem. 2013, 86, 952-957. [CrossRef]

3. Ketov, A. Glass Cullet: A Hard Way for Cellular Glass from Useless Waste; OmniScriptum GmbH \& Co.: Saarbruecken, Germany, 2017; p. 61, ISBN 978-3-330-65181-4.

4. Vaisman, Y.I.; Ketov, A.A.; Ketov, Y.A.; Molochko, R.A. Oxidation of carbon by water vapor in hydrate gas-formation mechanism in manufacture of cellular glass. Russ. J. Appl. Chem. 2015, 88, 382-385. [CrossRef]

5. Sivakumar, K.; Mohan, N.K. Performance analysis of downdraft gasifier for agriwaste biomass materials. Indian J. Sci. Technol. 2010, 3, 58-60.

6. Mansaray, K.G.; Ghaly, A.E. Physical and Thermochemical Properties of Rice Husk. Energy Sources 1997, 19, 989-1004. [CrossRef]

7. Romallosa, A.R.D.; Kraft, E. Feasibility of Biomass Briquette Production from Municipal Waste Streams by Integrating the Informal Sector in the Philippines. Resources 2017, 6, 12. [CrossRef]

8. Gomes, G.M.F.; Philipssen, C.; Bard, E.K.; Zen, L.D.; Souza, G. Rice husk bubbling fluidized bed combustion for amorphous silica synthesis. J. Environ. Chem. Eng. 2016, 4, 2278-2290. [CrossRef]

9. Rong, H.; Wang, T.; Zhou, M.; Wang, H.; Hou, H.; Xue, Y. Combustion Characteristics and Slagging during Co-Combustion of Rice Husk and Sewage Sludge Blends. Energies 2017, 10, 438. [CrossRef]

10. Bakar, R.A.; Yahya, R.; Gan, S.N. Production of High Purity Amorphous Silica from Rice Husk. Procedia Chem. 2016, 19, 189-195. [CrossRef]

11. Lu, Q.; Zhang, Z.; Liao, H.; Yang, X.; Dong, C. Lubrication Properties of Bio-Oil and Its Emulsions with Diesel Oil. Energies 2012, 5, 741-751. [CrossRef]

12. Mehmood, S.; Reddy, B.V.; Rosen, M.A. Energy Analysis of a Biomass Co-firing Based Pulverized Coal Power Generation System. Sustainability 2012, 4, 462-490. [CrossRef] 
13. Yuvakkumar, R.; Elango, V.; Rajendran, V.; Kannan, N. High-purity nano silica powder from rice husk using a simple chemical method. J. Exp. Nanosci. 2014, 9, 272-281. [CrossRef]

14. Shamsudin, R.; Azam, F.A.A.; Hamid, M.A.A.; Ismail, H. Bioactivity and Cell Compatibility of $\beta$-Wollastonite Derived from Rice Husk Ash and Limestone. Materials 2017, 10, 1188. [CrossRef] [PubMed]

15. Alyosef, H.A.; Roggendorf, H.; Schneider, D.; Inayat, A.; Welscher, J.; Schwieger, W.; Münster, T.; Kloess, G.; Ibrahim, S.; Enke, D. Comparative Study between Direct and Pseudomorphic Transformation of Rice Husk Ash into MFI-Type Zeolite. Molecules 2018, 23, 1. [CrossRef] [PubMed]

16. Alnahhal, M.F.; Alengaram, U.J.; Jumaat, M.Z.; Alqedra, M.A.; Mo, K.H.; Sumesh, M. Evaluation of Industrial By-Products as Sustainable Pozzolanic Materials in Recycled Aggregate Concrete. Sustainability 2017, 9, 767. [CrossRef]

17. Karim, R.; Hossain, M.; Khan, M.N.N.; Zain, M.F.M.; Jamil, M.; Lai, F.C. On the Utilization of Pozzolanic Wastes as an Alternative Resource of Cement. Materials 2014, 7, 7809-7827. [CrossRef] [PubMed]

18. Hwang, C.; Huynh, T. Effect of alkali-activator and rice husk ash content on strength development of fly ash and residual rice husk ash-based geopolymers. Constr. Build. Mater. 2015, 101, 1-9. [CrossRef]

19. Kalaw, M.E.; Culaba, A.; Hinode, H.; Kurniawan, W.; Gallardo, S.; Promentilla, M.A. Optimizing and Characterizing Geopolymersfrom Ternary Blend of Philippine Coal Fly Ash, Coal Bottom Ash and Rice Hull Ash. Materials 2016, 9, 580. [CrossRef] [PubMed]

20. Ziegler, D.; Formia, A.; Tulliani, J.; Palmero, P. Environmentally-Friendly Dense and Porous Geopolymers Using Fly Ash and Rice Husk Ash as Raw Materials. Materials 2016, 9, 466. [CrossRef] [PubMed]

21. Murri, A.N.; Medri, V.; Papa, E.; Laghi, L.; Mingazzini, C.; Landi, E. Porous Geopolymer Insulating Core from a Metakaolin/Biomass Ash Composite. Environments 2017, 4, 86. [CrossRef]

22. Hesky, D.; Aneziris, C.G.; Groß, U.; Horn, A. Water and waterglass mixtures for foam glass production. Ceram. Int. 2015, 41, 12604-12613. [CrossRef]

23. Vaisman, I.; Ketov, A.; Ketov, I. Cellular glass obtained from non-powder preforms by foaming with steam. Ceram. Int. 2016, 42, 15261-15268. [CrossRef]

24. Ahiduzzaman, M.; Islam, A.K.M.S. Energy Utilization and Environmental Aspects of Rice Processing Industries in Bangladesh. Energies 2009, 2, 134-149. [CrossRef]

25. Pedro, R.; Tubino, R.M.C.; Anversa, J.; de Col, D.; Lermen, R.T.; Silva, R. Production of Aerated Foamed Concrete with Industrial Waste from the Gems and Jewels Sector of Rio Grande do Sul-Brazil. Appl. Sci. 2017, 7, 985. [CrossRef] 